\title{
Thermodynamic Optimization of an Organic Rankine Cycle for Power Generation from a Low Temperature Geothermal Heat Source
}

\author{
Inés Encabo Cáceres Roberto Agromayor Lars O. Nord \\ Department of Energy and Process Engineering \\ Norwegian University of Science and Technology (NTNU) \\ Kolbjørn Hejes v.1B, NO-7491 \\ Trondheim, Norway \\ inesedstud.ntnu.no
}

\begin{abstract}
The increasing concern on environment problems has led to the development of renewable energy sources, being the geothermal energy one of the most promising ones in terms of power generation. Due to the low heat source temperatures this energy provides, the use of Organic Rankine Cycles is necessary to guarantee a good performance of the system. In this paper, the optimization of an Organic Rankine Cycle has been carried out to determine the most suitable working fluid. Different cycle layouts and configurations for 39 different working fluids were simulated by means of a Gradient Based Optimization Algorithm implemented in MATLAB and linked to REFPROP property library. The heat source was hot water from a geothermal reservoir with an inlet temperature of $120^{\circ} \mathrm{C}$ and an outlet temperature limit of $75^{\circ} \mathrm{C}$. For each working fluid, an optimal configuration was obtained, based on the optimization of the second law efficiency. In addition, a sensitivity analysis for the polytropic efficiencies of the pump and turbine was carried out. Results show that those working fluids with a critical temperature close to the maximum temperature of the cycle give the highest plant efficiencies (being propylene and R1234yf the best ones). Using a recuperator increases the plant efficiency in all cases with exception of wet working fluids. The cycles experiencing the highest sensitivity on the pump performance are those using working fluids with low critical temperatures. Increasing the number of stages of the turbine increases the overall plant efficiency for all working fluids, but some fluids are more sensitive to the turbine efficiency than others.
\end{abstract}

Keywords: Process modelling, process simulation, working fluid selection, parametric optimization, second law efficiency.

\section{Introduction}

Historically, the preferred methods for power generation have been related to Brayton or Rankine power cycles, fueled by natural gas or other fossil fuels (Macchi and Astolfi, 2017). However, during the last years, the increasing concern of the greenhouse effect and climate change has led to an increase of renewable energy, such as wind and solar power. In addition to these listed renewable energies, there is an energy source that shows a promising future due to the advantages it provides when compared to other renewable energies. This developing energy is geothermal energy, and its advantages are related to its availability (Macchi and Astolfi, 2017): it does not depend on the ambient conditions, it is stable, and it offers the possibility of renewable energy base load operation. One of the challenges of geothermal energy is that it does not provide very high temperatures, and this fact has made researches and engineers to focus their studies on how to obtain high thermodynamic efficiencies at low- and medium-temperature heat sources. One of the solutions for this problem are Organic Rankine Cycles (ORCs), which present a simple structure with a high reliability, an easy maintenance and, most importantly, a high potential to produce power from low source temperatures when compared to other power generation cycles (Saleh et al, 2007).

The design of the ORC requires a thorough analysis, since there are many parameters affecting its performance, and any change of these parameters will have a major impact on the efficiency of the cycle. With this aim, many different studies have been carried out. (Saleh et al, 2007) analyze the performance of 31 different working fluids, finding that those working fluids with the highest boiling temperatures are giving the highest efficiencies, being cyclopentane the best one for the given conditions and assumptions. (Roy et al, 2011), by means of a parametric ORC optimization, found that R123 is the best working fluid due to its high efficiency and high power production. (Hung et al, 2010) studied the efficiency of an ORC where benzene, ammonia, R11, R12, R1234a and R113, are used as the working fluids, differencing between wet, dry and isentropic working fluids and concluding that isentropic 
fluids are preferred for ORC systems, since they are giving the best efficiencies. (Shu et al, 2014) studied the thermal efficiency and exergy losses in an ORC, using pure hydrocarbons and mixtures; zeotropic mixtures seem to present a better thermodynamic performance than pure working fluids. These conclusions were also found by (Haberle et al, 2012), who use a mixture of ibutane and i-pentane for studying the second law efficiency.

Even though many studies have been carried out, none of them shows the same results regarding which is the best working fluid for an ORC with low heat source temperature, and all of them agree on the fact that the thermodynamic boundaries of the cycle, the working fluid selection, the constraints, and choice of the degrees of freedom are key parameters for analyzing and designing the cycle. In this work, a thermodynamic analysis has been carried out, focused on the optimization of the cycle (being the second law efficiency the objective function), analyzing more than 35 different pure working fluids from different classes, and investigating the pump and expander efficiencies impact on the cycle performance.

\section{Organic Rankine Cycle}

\subsection{Cycle design}

The ORC is the main technology used to transform low temperature thermal energy into electrical power. The heat is transferred to the working fluid in an evaporator (or primary heat exchanger), which evaporates and may superheat. Then, the working fluid reaches the expander, normally a turbine, in which it is expanded and experiences an enthalpy drop between the inlet and outlet, transforming the energy from the fluid into mechanical work. This mechanical work is transformed into electrical energy in a generator. After the expander, the working fluid reaches the condenser, where it rejects the surplus heat and changes its phase again. Once all the vapour has been condensed, the remaining liquid is pumped back to the evaporator. This is the simplest

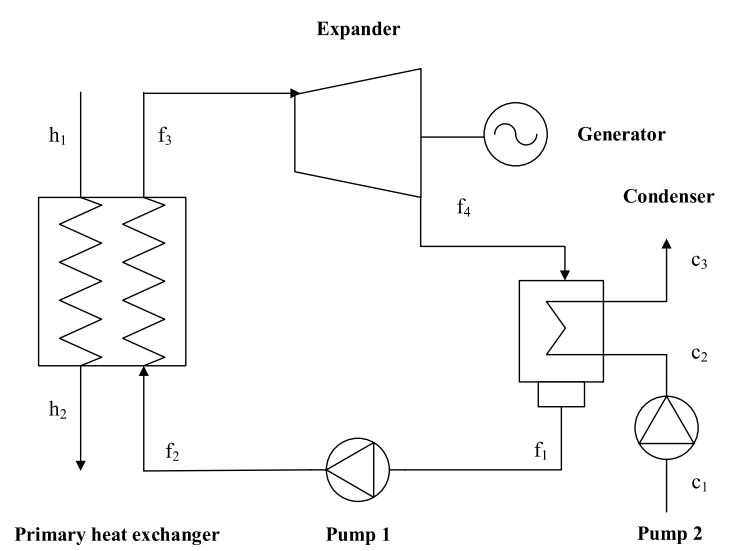

ORC, which can be seen in Figure 1, together with a typical T-s diagram for the same cycle layout.

This simple configuration can be modified to obtain higher efficiencies (by adding more pressure levels, different types of regeneration, reheating, etc). Multiple pressure levels are normally used when the available heat to be absorbed from the heat source is high; otherwise, the expensive and complex cycle layout would not be justified. The reheating unit is installed in the cycle when the amount of liquid that is formed during the expansion process is so high that it could damage the turbine (Macchi and Astolfi, 2017; Agromayor, 2017). For the case study of this work, the heat source does not provide a high temperature; therefore, multiple pressure levels and reheating configuration were not considered.

Regeneration is a common practice in ORC layouts. It is beneficial from a thermodynamic point of view when the fluid at the outlet of the expander is superheated vapour and there exists a limitation for the lower temperature of the heat source (Agromayor, 2017). Figure 2 shows the regenerative cycle layout. The regeneration allows to preheat the liquid that enters the primary heat exchanger, and, at the same time, to cool the superheated vapour coming out of the turbine. This results into lower cooling loads and smaller condensers. Both cycle layouts (the simple and the regenerated one) allow to work in different cycle configurations: saturated, superheated and transcritical. For this project, all the configurations were considered for each working fluid, to determine which one gives the best results in terms of efficiency.

\subsection{Working fluid selection}

The fluid selection for an ORC is the key parameter to design the cycle, meaning that it is the most important degree of freedom during its analysis. The complexity of the process is not just a consequence of the large amount of working fluids that can be found in the market, but also of the infinite number of mixtures that

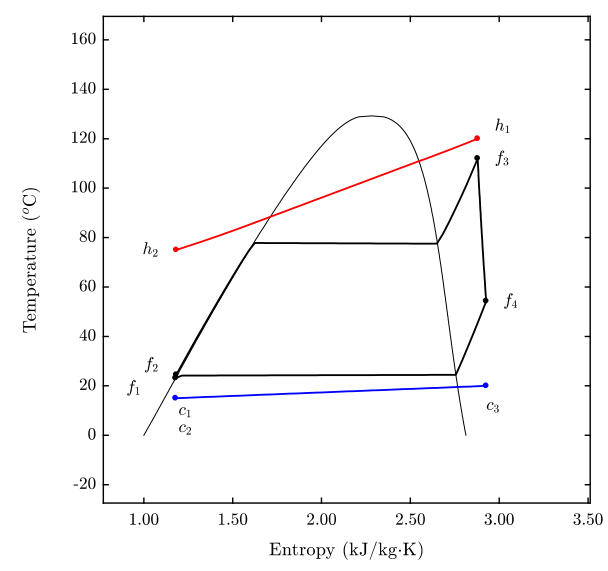

Figure 1. Simple ORC layout and typical T-s diagram for a random pure working fluid 

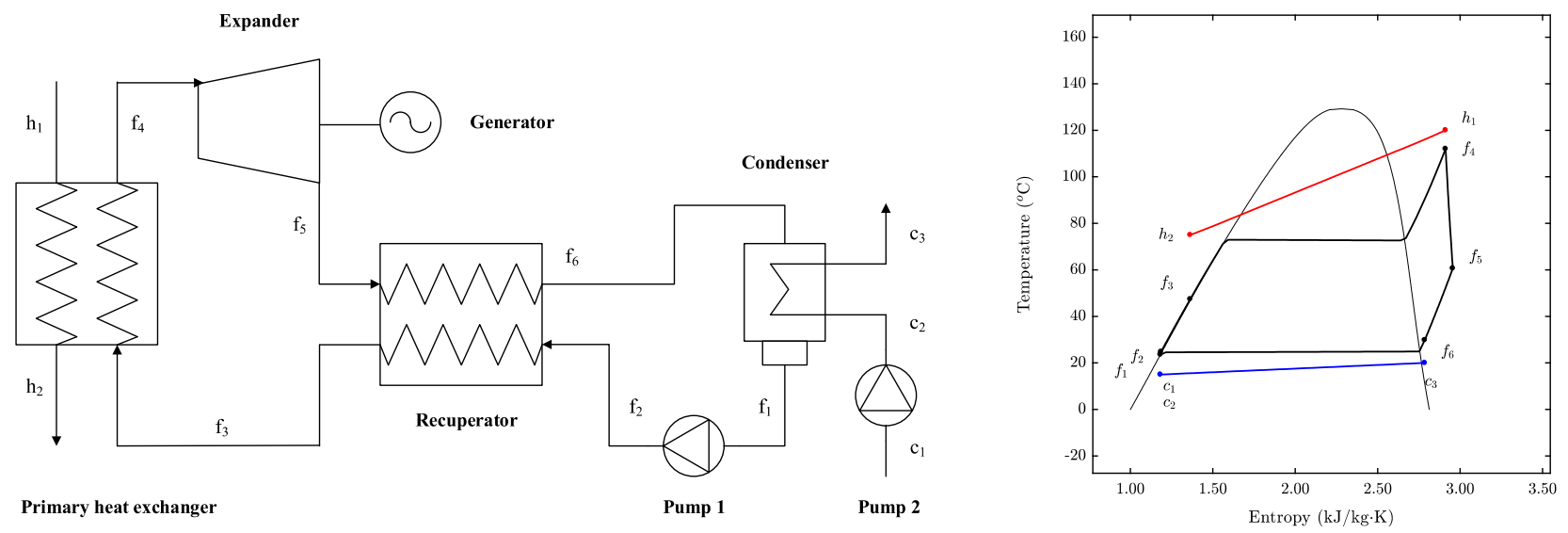

Figure 2. Recuperated ORC layout and typical T-s diagram for a random pure working fluid

can be obtained from these pure substances. Taking a decision when choosing the working fluid for the ORC has a major impact on the cost, the components and cycle performance and on the safety requirements (Macchi and Astolfi, 2017).

(Feng et al, 2015) propose the use of mixtures in the ORC, due to the non-isothermal change of phase in the evaporator, which allows to obtain better gliding temperature matches between the heat source and the working fluid. However, the analysis reflects that mixtures are not always giving better cycle performances than pure working fluids. Due to the high complexity that this problem has, the study of different mixtures was not included in this work.

The uncertainty fluid properties can influence the reliability of the optimized cycles, and, for this reason J. Frutiger et al. propose in (Frutiger et al, 2016) an analysis of the impact of uncertainty of the fluid properties in the behavior of the ORC, including the Molecular Weight (MW), critical temperature, critical pressure and acentric factor. This gives an idea of how important the working fluid properties are when choosing the working fluid. There are different factors or properties to consider when taking this decision, and we can find, among others (Macchi and Astolfi, 2017):

- The molecular complexity. It influences the T-s diagram shape (differencing between dry, isentropic and wet fluids) which is essential for the performance of the turbine, since it determines the amount of liquid that may be formed during the expansion. (Zhai et al, 2014) demonstrate that complex molecules that include double bonds or cycle bonds are much more efficient than molecules with only single bonds, with a lower molecular complexity

- The molecular mass. This parameter has a major influence on the design of the turbine. When the molecular weight increases, the enthalpy drop in the turbine is lower, and this is translated into a need of less stages for the expansion, lower peripheral velocities and mechanical stresses, although the heat transfer coefficient diminishes and heat exchangers with larger heat transfer areas are needed (higher costs).

- The critical temperature. It is recommended to use working fluids with critical temperatures as closest as possible to the highest temperature of the cycle, since they guarantee an efficient heat exchange process.

The impact of the working fluid on the environment is important. Fluids with a high Ozone Depletion Potential (ODP) are undesirable, while organic fluorinated fluids (HFCs) are to be avoided because of their high Global Warming Potential (GWP). From (Zhai et al, 2014) it was found that the GWP is not only important for the environment concern, but also for the efficiency of the cycle (results show that those working fluids with a GWP lower than 1500 can absorb more energy from the heat source, improving the cycle efficiency).

The most common working fluid for conventional Rankine cycles is $\mathrm{H}_{2} \mathrm{O}$. However, when the heat source temperature is low, $\mathrm{H}_{2} \mathrm{O}$ shows poor performances. As $\mathrm{H}_{2} \mathrm{O}$ is a wet working fluid, it condensates during the expansion, and this may damage the turbine. To solve this problem, $\mathrm{H}_{2} \mathrm{O}$ requires a too high degree of superheating and a low enthalpy drop across the expander, meaning that the power produced is low (low plant efficiencies). It was found to be of interest to investigate how $\mathrm{H}_{2} \mathrm{O}$ behaves in our case of study even if the performance was expected to be poor.

\section{Methodology}

The Rankine cycle model was implemented in MATLAB and optimized with a Gradient Based Algorithm (Sequential Quadratic Programming, SQP). The advantage of Gradient Based Algorithms against the popular direct search algorithms, such as the Genetic Algorithm, is that the former has a faster convergence rate. The code can simulate and optimize both the simple 
and the recuperated Rankine cycles and it computes all the thermodynamic states of the cycle, using the REFPROP library.

\subsection{Fluid screening selection}

Most of the manufacturers opt to work with organic fluids that have already been tried, to reduce the uncertainty and simplify the fluid selection process. However, this does not necessarily mean that they are the best choice. In fact, (Colonna et al, 2015) insist on the need of carrying out research on new substances. In this work, some of the most used working fluids were analyzed, although others fluids that are not so well known were also included. After a literature search, we found that the most commonly used organic working fluids for ORC applications are: R134a, R245fa, npentane, octamethultrisiloxane, toluene (Maraver et al, 2014), and, among the hydrocarbons (HCs), butane (R600), iso-butane (R600a), pentane (R601), isopentane (R601a) and hexane (Liu et al, 2013).

To select the working fluid, we took as a starting point a list of more than 130 different pure substances. Since not all of these pure substances were suitable for the given conditions, a first screening selection based on the need of meeting four main requirements was carried out to discard unsuitable working fluids. The requirements were:

1. The ODP had to be zero or close to zero

2. The GWP must be lower than 2000

3. The fluid critical temperature needed to be higher than the ambient temperature to make condensation possible

4. The saturation pressure at ambient temperature had to be higher than $1 \mathrm{kPa}$ to limit vacuum in the condenser

From these requirements, a revised list of 44 working fluids was obtained. 39 working fluids were simulated and optimized by means of the Gradient Based Algorithm in MATLAB.

\subsection{Assumptions and boundary conditions}

The main assumptions and boundary conditions can be found in Table 1. Some data such as the pump and turbine efficiencies were assumed based on the information found during the literature review process, although the impact of these parameters was studied by means of a sensitivity analysis.

Values for the pump polytropic efficiency between $10 \%$ and $100 \%$ were simulated for the most optimal working fluids under subcritical and transcritical conditions. For the expander, the correlation from (Astolfi and Macchi, 2015) for axial turbines of one, two, and three stages to compute the polytropic efficiency as a function of the volume ratio and the size parameter was also analyzed for some of the best working fluids. This correlation states:

$$
\begin{gathered}
\eta_{\text {turb }}=f\left(V_{r}, S P\right) \\
V_{r}=\frac{\rho_{\text {in }}}{\rho_{\text {out }}} \\
S P=\frac{\left(\dot{m}_{\text {out }} / \rho_{\text {out }, s}\right)^{1 / 2}}{\left(\Delta h_{S}\right)^{1 / 4}}
\end{gathered}
$$

\begin{tabular}{|c|c|c|}
\hline \multicolumn{3}{|l|}{ Hot source } \\
\hline$T_{h, \text { in }}$ & {$\left[{ }^{\circ} \mathrm{C}\right]$} & 120 \\
\hline$T_{\text {hmin,out }}$ & {$\left[{ }^{\circ} \mathrm{C}\right]$} & 75 \\
\hline$T_{\text {hmax,out }}$ & {$\left[{ }^{\circ} \mathrm{C}\right]$} & 85 \\
\hline$\dot{m}$ & {$[\mathrm{~kg} / \mathrm{s}]$} & 13.23 \\
\hline$P_{\text {out }}$ & [bar] & 3 \\
\hline Working fluid & {$[-]$} & $\mathrm{H}_{2} \mathrm{O}$ \\
\hline \multicolumn{3}{|l|}{ Cold source } \\
\hline$T_{i n}$ & {$\left[{ }^{\circ} \mathrm{C}\right]$} & 10 \\
\hline Working fluid & {$[-]$} & $\mathrm{H}_{2} \mathrm{O}$ \\
\hline$\Delta T_{c, \max }$ & {$\left[{ }^{\circ} \mathrm{C}\right]$} & 10 \\
\hline$\Delta T_{c, \min }$ & {$\left[{ }^{\circ} \mathrm{C}\right]$} & 5 \\
\hline \multicolumn{3}{|l|}{ Ambient conditions } \\
\hline$P_{a m b}$ & [bar] & 1.013 \\
\hline$T_{a m b}$ & {$\left[{ }^{\circ} \mathrm{C}\right]$} & 15 \\
\hline \multicolumn{3}{|l|}{ Pinch points } \\
\hline$\overline{\Delta T_{\max }}$ & {$\left[{ }^{\circ} \mathrm{C}\right]$} & 8 \\
\hline$\Delta T_{\min }$ & {$\left[{ }^{\circ} \mathrm{C}\right]$} & 5 \\
\hline \multicolumn{3}{|l|}{ Pressure drops } \\
\hline$\overline{\Delta P(\text { evap,cond,rec })}$ & [bar] & $0.01 \cdot P_{\text {in }}$ \\
\hline \multicolumn{3}{|l|}{ Pump } \\
\hline Polytropic efficiency & {$[\%]$} & 70 \\
\hline \multicolumn{3}{|l|}{ Turbine } \\
\hline Polytropic efficiency & {$[\%]$} & 80 \\
\hline
\end{tabular}

Table 1. Assumptions and boundary conditions.

Regarding the minimum outlet temperature of the hot source, the limitation was given to allow for use of the remaining heat in a low-temperature district heating system (this system is not considered in this work).

\subsection{Objective function}

Defining the objective function is crucial when it comes to optimizing the cycle. For this work, the variable to be optimized was the second law efficiency of the plant. A natural choice would have been optimizing the net power output or the first law efficiency (these three objective functions would give the same thermodynamic optimum), but optimizing the second law efficiency gives insight about how much potential for improvement is left.

The parameter to be optimized was the second law efficiency of the whole power plant, considering the recovery efficiency in the main heat exchanger. This is because not all the heat which was available from the heat source could be used (due to the limitation of the 
hot source outlet temperature). The plant second law efficiency, cycle second law efficiency and recovery second law efficiency are related according to Equations. 4-5-6.

$$
\begin{gathered}
\eta_{\text {II.cycle }}=\frac{\dot{W}_{\text {net }}}{\dot{E}_{\text {in }}} \\
\eta_{\text {II.rec }}=\frac{\dot{E}_{\text {in }}}{\dot{E}_{\text {max }}} \\
\eta_{\text {II.plant }}=\frac{\dot{W}_{\text {net }}}{\dot{E}_{\text {max }}}=\eta_{\text {II.cycle }} \cdot \eta_{\text {II.rec }}
\end{gathered}
$$

Where $\dot{E}_{\text {max }}$ is the maximum exergy flow rate that can be extracted from the hot source (if the hot source stream is cooled down to ambient conditions, $T_{0}=15^{\circ} \mathrm{C}$ and $p_{0}=1.013 \mathrm{bar}$ ). All these equations were applied to the list of working fluids which have been studied (see Table 2).

The first law efficiency can be defined as:

$$
\eta_{I . p l a n t}=\frac{\dot{W}_{n e t}}{\dot{Q}_{\text {in } \max }}
$$

\begin{tabular}{|c|c|c|c|c|}
\hline & Chemical name & Alternative name & Class & $\mathrm{T}_{\text {crit }} / \mathrm{T}_{\text {hot,in }}$ \\
\hline 1 & Methyl alcohol & Methanol & Alcohol & 1.3038 \\
\hline 2 & Ethyl alcohol & Ethanol & Alcohol & 1.3092 \\
\hline 3 & Ethane & $\mathrm{R} 170$ & Alkane & 0.7766 \\
\hline 4 & Propane & R290 & Alkane & 0.9408 \\
\hline 5 & 2-Methylpropane & Isobutane - R600a & Alkane & 1.0373 \\
\hline 6 & Butane & R600 & Alkane & 1.0813 \\
\hline 7 & 2,2-Dimethylpropane & Neopentane & Alkane & 1.1032 \\
\hline 8 & 2-Methylbutane & Isopentane - R601a & Alkane & 1.1709 \\
\hline 9 & Pentane & R601 & Alkane & 1.1947 \\
\hline 10 & 2-Metylpentane & Isohexane & Alkane & 1.2659 \\
\hline 11 & Hexane & - & Alkane & 1.2917 \\
\hline 12 & Heptane & - & Alkane & 1.3739 \\
\hline 13 & Propene & Propylene - R1270 & Alkene & 0.9283 \\
\hline 14 & 2-Methyl-1-propene & Isobutene & Alkene & 1.0634 \\
\hline 15 & Ethylethylene & 1-Butene & Alkene & 1.0665 \\
\hline 16 & Cis-2-butene & Cis-butene & Alkene & 1.1084 \\
\hline 17 & Propyne & - & Alkyne & 1.0235 \\
\hline 18 & Benzene & Benzol & Aromatic & 1.4295 \\
\hline 19 & Methylbenzene & Toluene & Aromatic & 1.5052 \\
\hline 20 & Dimethyl carbonate & $\mathrm{DMC}$ & Carbonate ester & 1.4168 \\
\hline 21 & Cyclopropane & - & Cycloalkane & 1.0131 \\
\hline 22 & Cyclopentane & - & Cycloalkane & 1.3016 \\
\hline 23 & Cyclohexane & - & Cycloalkane & 1.4081 \\
\hline 24 & Dimethylether & DME & Ether & 1.0184 \\
\hline 25 & Fluoromethane & R41 & $\mathrm{HFC}$ & 0.8070 \\
\hline 26 & Difluoromethane & R32 & $\mathrm{HFC}$ & 0.8934 \\
\hline 27 & 1,1,1,2-Tetrafluoroethane & $\mathrm{R} 134 \mathrm{a}$ & $\mathrm{HFC}$ & 0.9518 \\
\hline 28 & Fluoroethane & R161 & $\mathrm{HFC}$ & 0.9545 \\
\hline 29 & 1,1-Difluoroethane & R152a & $\mathrm{HFC}$ & 0.9829 \\
\hline 30 & 1,1,1,3,3-Pentafluoropropane & R245fa & $\mathrm{HFC}$ & 1.0865 \\
\hline 31 & 1,1,2,2,3-Pentafluoropropane & $\mathrm{R} 245 \mathrm{ca}$ & $\mathrm{HFC}$ & 1.1384 \\
\hline 32 & 1,1,1,3,3-Pentafluorobutane & $\mathrm{R} 365 \mathrm{mfc}$ & $\mathrm{HFC}$ & 1.1700 \\
\hline 33 & 2,3,3,3-Tetrafluoroprop-1-ene & R1234yf & $\mathrm{HFO}$ & 0.9356 \\
\hline 34 & Trans-1,3,3,3-tetrafluoropropene & R1234ze & $\mathrm{HFO}$ & 0.9729 \\
\hline 35 & Propanone & Acetone & Ketone & 1.2924 \\
\hline 36 & Hexamethyldisiloxane & $\mathrm{MM}$ & Linear Siloxane & 1.3193 \\
\hline 37 & Carbon Dioxide & $\mathrm{CO}_{2}-\mathrm{R} 744$ & Inorganic & 0.7736 \\
\hline 38 & Ammonia & R717 & Inorganic & 1.0312 \\
\hline 39 & $\mathrm{H}_{2} \mathrm{O}$ & R718 & Inorganic & 1.6459 \\
\hline
\end{tabular}

Where $\dot{Q}_{\text {in,max }}$ is the maximum heat flow rate that can be extracted from the hot source

Table 2. List of studied and simulated working fluids 


\subsection{Degrees of freedom and constraints}

When it comes to optimize an ORC, choosing the constraints and defining the degrees of freedom is of special importance. For this work, the simple cycle had 6 degrees of freedom, while the recuperated one had 7. These degrees of freedom were defined as dimensionless parameters related to the cycle variables which have maximum and minimum values, and take values between 0 and 1 .

$x_{1} \quad$ Heat source outlet temperature

$x_{2} \quad$ Condenser temperature jump

$x_{3} \quad$ Pressure at the inlet of the turbine

$x_{4} \quad$ Pressure at the outlet of the turbine

$x_{5} \quad$ Enthalpy at the inlet of the turbine

$x_{6}$ Enthalpy at the inlet of the primary heat exchanger

$x_{7} \quad$ Enthalpy at the outlet of the condenser (only for the recuperated cycle

Regarding the constraints, they are the same for the simple and the recuperated cycles. These are:

$c_{1} \quad$ The working fluid has to be subcooled at the inlet of the pump to avoid cavitation

$c_{2}$ If the pressure is subcritical, the working fluid has to be subcooled at the inlet of the evaporator to avoid the phase change in the recuperator

$c_{3}$ If the pressure is subcritical, the working fluid has to be saturated or superheated at the outlet of the evaporator (avoid trilateral and partial evaporation cycles)

$c_{4} \quad$ The working fluid has to be saturated or superheated at the outlet of the expander (avoid vapour qualities lower than 1)

$c_{5}$ The pinch point in the evaporator has to be higher than the minimum temperature difference specified to avoid temperature crossing

$c_{6} \quad$ The pinch point in the condenser has to be higher than the minimum temperature difference specified to avoid temperature crossing

$c_{7} \quad$ The pinch point in the recuperator has to be higher than the minimum temperature difference specified to avoid temperature crossing

\section{Results and discussion}

\subsection{Thermodynamic analysis}

Some of the obtained results can be found in Table 3, which includes the working fluid mass flow, turbine and pump powers, net power output and first and second law efficiencies for the plant. The best obtained results for each different working fluid family have been included.

Figure 3 shows the results of the thermodynamic optimization as a function of the ratio of the critical temperature to the highest temperature of the cycle (hot source inlet temperature). Results show that those cycles with $\mathrm{T}_{\text {crit }} / \mathrm{T}_{\text {hot,in }}$ between 0.93 and 1.02 are giving the best plant second law efficiencies (between $31.33 \%$ and
$33.46 \%$ ). For values of $\mathrm{T}_{\text {crit }} / \mathrm{T}_{\text {hot,in }}$ lower than 0.9 , the second law efficiency considerably drops, reaching values down to $21 \%$, which correspond to fluids such as $\mathrm{R} 41, \mathrm{CO}_{2}$ or ethane, whose best cycle configuration is the transcritical one. The reason for this is that, when the $\mathrm{T}_{\text {hot,in }}$ is above the critical temperature, the best match between the hot source and the working fluid in the primary heat exchanger is found when the working fluid operates above its critical pressure. This is consistent with the conclusions from (Hærvig, 2016; Xu and Liu, 2013). The rest of the working fluids show their best performance at subcritical conditions, except for propylene and R1234yf. For $\mathrm{T}_{\text {crit }} / \mathrm{T}_{\text {hot,in }}$ values higher than 1.02, the performance of the cycle is slightly worse than the one found for the most optimal working fluids, although the difference found for the second law efficiency is not large. The working fluids showing the worst performance for the analyzed range were ammonia (recuperated) and methanol. The reason for this is that they are wet fluids and, in case of the ammonia, it has no potential for heat recovery (what is more, the recuperator would decrease the temperature at the inlet of the evaporator and the cycle efficiency). For the rest of the working fluids, the efficiencies are all above $31 \%$, showing a better performance when the recuperator unit is installed.

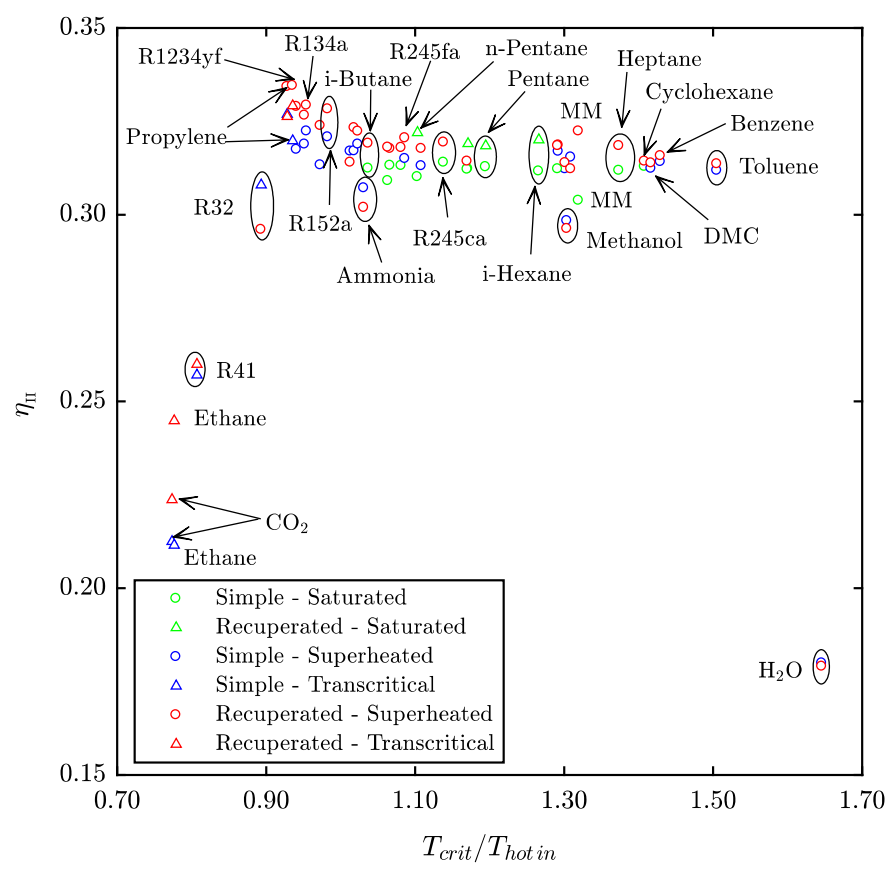

Figure 3. Influence of the relationship between the working fluid critical temperature and the highest cycle temperature on the plant second law efficiency

As it happens when the $\mathrm{H}_{2} \mathrm{O}$ is used as the working fluid, some wet fluids require superheating to prevent condensation during the expansion (Bao and Zhao, 2013). For example, ammonia, $\mathrm{H}_{2} \mathrm{O}$, and ethanol (wet 
fluids) require a high degree of superheating, while some isentropic fluids such as the R245fa or R365mfc require a low one. Most of the dry working fluids such as the butane heptane or n-pentane are operating at saturated conditions due to the positive slope of their diagram, which avoids the need of superheating the working fluid before its expansion.

As Figure 3 and Table 3 show, the working fluids giving the highest potential of improvement are alkanes, followed by the HFOs and HFCs, while the cycloalkanes do not show an appreciable efficiency increase when installing a recuperator unit. Even though ethane is the working fluid showing the highest potential of improvement when installing a recuperator unit, its performance is still one of the worst among all the analyzed working fluids. The highest efficiency gains are observed for the dry working fluids, because they have higher recuperation potentials than wet working fluids (ethanol and methanol experience an efficiency drop of $0.22 \%$ and $0.32 \%$ respectively when a regenerator unit is used). For the simple cycle layout, propylene shows the best results, operating at transcritical conditions and reaching an efficiency of $32.69 \%$. For the recuperated cycle, R1234yf becomes the best working fluid, reaching a second law plant efficiency of $33.46 \%$. It can also be seen that, while for the simple cycle layout many fluids are working at saturated conditions, for the recuperated configuration they show a better performance operating at superheated conditions. The reason is that a higher power production can be achieved when superheating, but this makes the cooling load to be higher (Bao and Zhao, 2013) unless a recuperator is used to decrease the cooling load and avoid wasted heat.

Regarding inorganic working fluids, the results for ammonia deviate from the tendency of Figure 3, while the $\mathrm{H}_{2} \mathrm{O}$ is giving the worst performance. For both $\mathrm{H}_{2} \mathrm{O}$ and ammonia, the recuperator is cooling down the working fluid at the inlet of the evaporator. Also, $\mathrm{H}_{2} \mathrm{O}$ is giving the lowest power output. This is a consequence of the too low enthalpy drop taking place across the turbine for avoiding wet expansion. Regarding $\mathrm{CO}_{2}$, it is also giving a low second law efficiency that improves with the use of a recuperator but it is still lower than the one for the rest of organic fluids. The results of this work indicate that the studied inorganic working fluids are not recommended for power generation in Rankine Cycles with low-heat source temperatures and low power capacities.

The Backwork Ratio (BWR) was plotted as a function of $\mathrm{T}_{\text {crit }}$ in Figure 4. It can be seen that those working fluids with the lowest critical temperatures (from $0^{\circ} \mathrm{C}$ to $92^{\circ} \mathrm{C}$ ) are giving the highest BWRs. For subcritical cycles with a critical temperature between $100^{\circ} \mathrm{C}$ and $160^{\circ} \mathrm{C}$, the simple cycles have higher BWRs than the recuperated cycles, due to the lower power production and higher power consumption they have.
For those working fluids with critical temperatures higher than $160^{\circ} \mathrm{C}$, the BWRs of the recuperated and simple cycles are very similar, since they can operate at lower pressures, guaranteeing a low pump power that does not appreciably change when moving from one cycle layout to another.

Finally, for toluene, the working fluid with the highest critical temperature, the maximum pressure to guarantee an efficient heat transfer process is the lowest one $(0.33 \mathrm{bar})$, and this results into the lowest power consumption among all the results (only $0.39 \mathrm{~kW}$ ), giving the lowest BWR.

The choice of the working fluid depends on the application at hand. If the target is power generation, the working fluids giving the highest second law efficiencies (those ones with a critical temperature close to the highest temperature of the cycle) should be chosen. Among these fluids, an economic analysis should be carried out to determine whether the use of a recuperator is justified or not. For those working fluids with a low second law efficiency, the power production is lower when comparing to the rest, and, since the amount of heat into the cycle is fixed, the heat rejected in the condenser is higher. This means that those working fluids with a low second law efficiency may have a promising potential for co-generation if the rejected heat in the condenser is used. For example, the ethane, with a second law efficiency of $21.15 \%$ rejects $2326.23 \mathrm{~kW}$ in the condenser at an inlet temperature of almost $56{ }^{\circ} \mathrm{C}$, while the recuperated propylene rejects $2225.36 \mathrm{~kW}$ with a plant efficiency of $33.42 \%$ and an inlet condenser temperature lower than $32^{\circ} \mathrm{C}$.

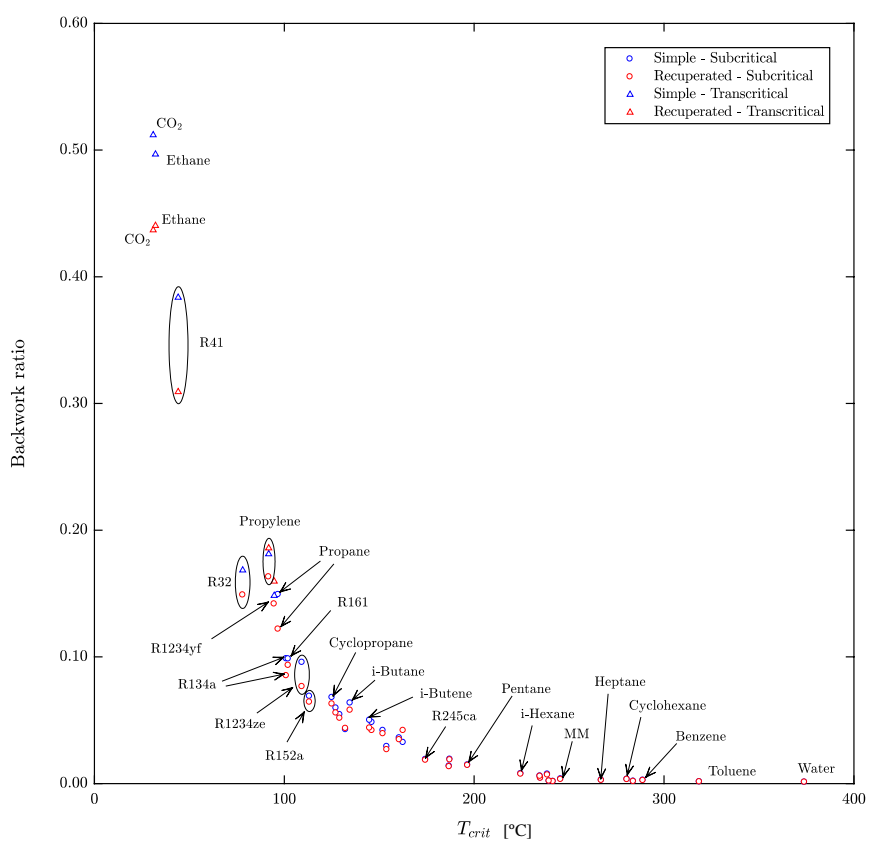

Figure 4. Influence of the critical temperature on the BWR for all the simulated working fluids 
Table 3. Main obtained results

\begin{tabular}{|c|c|c|c|c|c|c|c|c|}
\hline Fluid & Cycle layout & $\begin{array}{l}\text { Cycle } \\
\text { configuration }\end{array}$ & $\dot{m}_{w . f}$ & $\dot{W}_{t u r b}$ & $\dot{W}_{\text {pump }}$ & $\dot{W}_{\text {net }}$ & $\eta_{\text {I.plant }}$ & $\eta_{\text {II.plant }}$ \\
\hline$[-]$ & {$[-]$} & {$[-]$} & {$[\mathrm{kg} / \mathrm{s}]$} & {$[k W]$} & {$[k W]$} & {$[k W]$} & [\%] & [\%] \\
\hline Acetone & Simple & Subcritical & 3.83 & 274.76 & 1.23 & 273.53 & 4.69 & 31.69 \\
\hline Ammonia & Simple & Subcritical & 1.91 & 276.88 & 11.80 & 265.08 & 4.55 & 30.71 \\
\hline Benzene & Simple & Subcritical & 4.64 & 271.89 & 0.71 & 271.17 & 4.66 & 31.41 \\
\hline Butane & Simple & Subcritical & 5.64 & 282.08 & 11.84 & 270.24 & 4.64 & 31.31 \\
\hline Cis-butene & Simple & Subcritical & 5.36 & 279.29 & 9.06 & 270.23 & 4.64 & 31.30 \\
\hline $\mathrm{CO}_{2}$ & Simple & Transcritical & 12.00 & 375.77 & 192.37 & 183.40 & 3.15 & 21.25 \\
\hline Cyclopropane & Simple & Subcritical & 4.87 & 293.58 & 19.95 & 273.62 & 4.70 & 31.70 \\
\hline $\mathrm{DMC}$ & Simple & Subcritical & 4.73 & 270.10 & 0.50 & 269.60 & 4.63 & 31.23 \\
\hline DME & Simple & Subcritical & 4.87 & 291.00 & 17.36 & 273.65 & 4.70 & 31.70 \\
\hline Ethanol & Simple & Subcritical & 2.38 & 272.65 & 0.47 & 272.18 & 4.67 & 31.54 \\
\hline i-Hexane & Simple & Subcritical & 5.64 & 271.14 & 2.14 & 269.00 & 4.62 & 31.16 \\
\hline MM & Simple & Subcritical & 7.75 & 263.19 & 0.97 & 262.22 & 4.50 & 30.38 \\
\hline Propane & Simple & Subcritical & 5.91 & 322.06 & 48.05 & 274.00 & 4.70 & 31.74 \\
\hline Propylene & Simple & Transcritical & 6.15 & 344.63 & 62.44 & 282.19 & 4.84 & 32.69 \\
\hline Propyne & Simple & Subcritical & 4.27 & 291.07 & 15.85 & 275.22 & 4.72 & 31.88 \\
\hline R134a & Simple & Subcritical & 10.75 & 305.29 & 30.1 & 275.19 & 4.72 & 31.88 \\
\hline R152a & Simple & Subcritical & 7.05 & 297.40 & 20.50 & 276.91 & 4.75 & 32.08 \\
\hline R161 & Simple & Subcritical & 5.91 & 308.65 & 30.38 & 278.27 & 4.78 & 32.24 \\
\hline R1234yf & Simple & Transcritical & 13 & 324.11 & 48.09 & 276.02 & 4.74 & 31.98 \\
\hline R1234ze & Simple & Subcritical & 12.16 & 299.04 & 28.62 & 270.42 & 4.64 & 31.33 \\
\hline Toluene & Simple & Subcritical & 0.96 & 269.53 & 0.40 & 269.13 & 4.62 & 31.18 \\
\hline Water & Simple & Subcritical & 0.96 & 155.44 & 0.18 & 155.26 & 2.67 & 17.99 \\
\hline Acetone & Recuperated & Subcritical & 4.13 & 276.81 & 1.19 & 275.63 & 4.72 & 31.86 \\
\hline Ammonia & Recuperated & Subcritical & 1.89 & 273.08 & 11.91 & 261.18 & 4.47 & 30.19 \\
\hline Benzene & Recuperated & Subcritical & 5.09 & 273.85 & 0.68 & 273.17 & 4.68 & 31.57 \\
\hline Butane & Recuperated & Subcritical & 6.01 & 286.31 & 11.27 & 275.03 & 4.71 & 31.79 \\
\hline $\mathrm{CO}_{2}$ & Recuperated & Transcritical & 12.59 & 343.64 & 150.12 & 193.53 & 3.32 & 22.37 \\
\hline Cyclohexane & Recuperated & Subcritical & 5.75 & 272.76 & 0.90 & 271.86 & 4.66 & 31.43 \\
\hline DMC & Recuperated & Subcritical & 5.26 & 271.96 & 0.47 & 271.49 & 4.65 & 31.38 \\
\hline DME & Recuperated & Subcritical & 5.43 & 296.11 & 16.51 & 279.61 & 4.79 & 32.32 \\
\hline Heptane & Recuperated & Subcritical & 5.98 & 276.23 & 0.72 & 275.51 & 4.72 & 31.85 \\
\hline i-Hexane & Recuperated & Subcritical & 6.48 & 278.96 & 2.08 & 276.88 & 4.74 & 32.01 \\
\hline i-butane & Recuperated & Subcritical & 6.58 & 293.03 & 16.97 & 276.06 & 4.73 & 31.91 \\
\hline Methanol & Recuperated & Subcritical & 1.91 & 256.80 & 0.52 & 256.27 & 4.39 & 29.62 \\
\hline MM & Recuperated & Subcritical & 9.40 & 279.85 & 0.94 & 278.91 & 4.78 & 32.24 \\
\hline n-Pentane & Recuperated & Subcritical & 7.40 & 288.55 & 10.00 & 278.55 & 4.77 & 32.20 \\
\hline Propane & Recuperated & Subcritical & 6.34 & 324.08 & 39.52 & 284.56 & 4.87 & 32.89 \\
\hline Propylene & Recuperated & Subcritical & 6.31 & 345.57 & 56.41 & 289.17 & 4.95 & 33.42 \\
\hline Propylene & Recuperated & Transcritical & 6.31 & 346.72 & 64.43 & 282.29 & 4.84 & 32.63 \\
\hline Propyne & Recuperated & Subcritical & 4.68 & 294.02 & 15.17 & 278.85 & 4.78 & 32.23 \\
\hline $\mathrm{R} 134 \mathrm{a}$ & Recuperated & Subcritical & 13.16 & 308.82 & 26.31 & 282.50 & 4.84 & 32.66 \\
\hline R152a & Recuperated & Subcritical & 7.74 & 303.48 & 19.53 & 283.96 & 4.86 & 32.82 \\
\hline R161 & Recuperated & Subcritical & 6.34 & 314.20 & 29.34 & 284.86 & 4.88 & 32.93 \\
\hline R245fa & Recuperated & Subcritical & 11.42 & 284.94 & 7.63 & 277.31 & 4.75 & 32.05 \\
\hline R1234yf & Recuperated & Transcritical & 14.41 & 337.61 & 53.89 & 283.73 & 4.88 & 32.92 \\
\hline R1234yf & Recuperated & Subcritical & 14.48 & 337.26 & 47.84 & 289.42 & 4.96 & 33.46 \\
\hline R1234ze & Recuperated & Subcritical & 13.90 & 303.39 & 23.24 & 280.16 & 4.80 & 32.38 \\
\hline Toluene & Recuperated & Subcritical & 5.35 & 271.63 & 0.38 & 271.25 & 4.65 & 31.36 \\
\hline $\mathrm{H}_{2} \mathrm{O}$ & Recuperated & Subcritical & 0.96 & 154.92 & 0.18 & 154.74 & 2.65 & 17.90 \\
\hline
\end{tabular}




\subsection{Pump sensitivity analysis}

Geothermal energy allows to work at part-load conditions when desired. (Landelle et al, 2017) stated efficiency losses of more than a $50 \%$ when operating below the nominal power plant conditions, and this, joint to the fact that each working fluid has a single and limited operating range in which it is optimal (Hærvig, 2016) has led to the conclusion that a pump sensitivity analysis should be carried out in this work. In this sensitivity analysis, one of the goals is to determine which working fluid is the optimal and for which range of pump polytropic efficiency, setting the nominal pump efficiency as $70 \%$ based on the literature review (Brosukiewicz-Gozdur, 2013). The analysis was then performed for 5 different working fluids. These were:

- Toluene: Working fluid operating under subcritical conditions with the lowest power consumption

- R161: Working fluid operating under subcritical conditions with the highest power consumption

- R1234yf: Working fluid operating under transcritical conditions with the lowest power consumption

- $\mathrm{CO}_{2}$ : Working fluid operating under transcritical conditions with the highest power consumption

- Propylene: Best working fluid for the nonrecuperated layout.

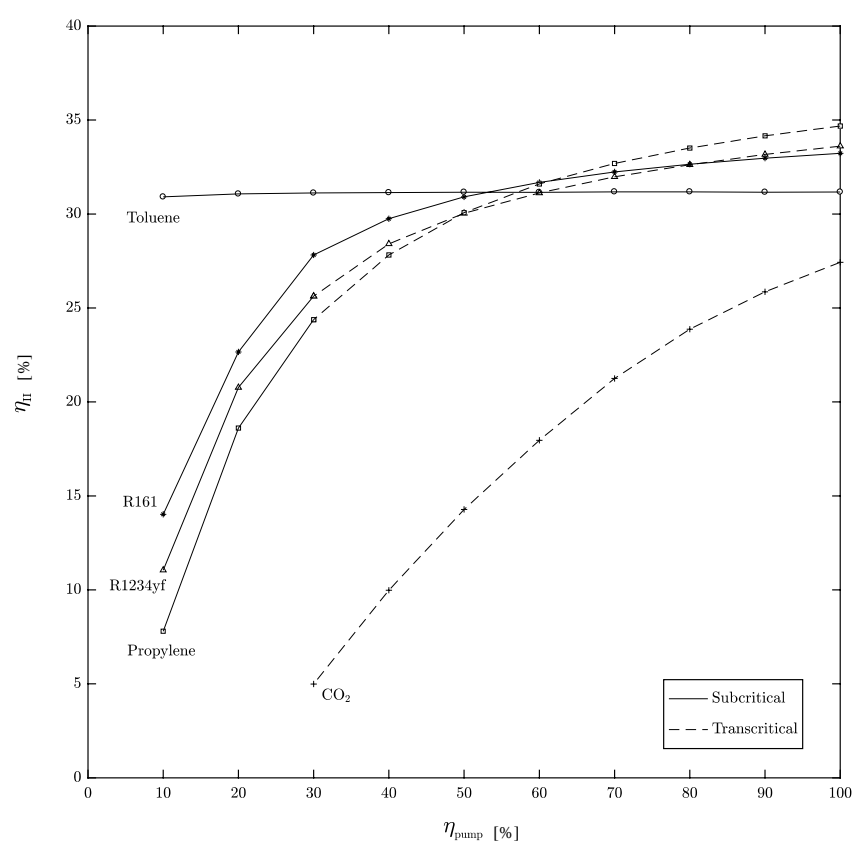

Figure 5. Effect of the pump polytropic efficiency on the overall plant second law efficiency for different working fluids

Efficiencies from $10 \%$ to $100 \%$ were analyzed for all these fluids. Results for the second law plant efficiency can be found in Figure 5. It can be seen that the second law efficiency suffers a great variation for all the fluids except for toluene. $\mathrm{CO}_{2}$ shows the greatest variation, because it is the working fluid that requires the highest power consumption in the pump (high operating pressures), and any small change in the pump polytropic efficiency leads to important changes on the net power output and plant efficiency. For pump efficiencies reduced below $30 \%$, the efficiency of the plant turns out to be negative (the power consumption is higher than the power produced in the expander). Even at a $100 \%$ pump efficiency, the $\mathrm{CO}_{2}$ would still be the worst working fluid because of other irreversibilities in the cycle. The pump efficiency determines which working fluid is the best one at each operating point. Toluene is found to be the working fluid giving the second worst efficiency for efficiencies higher than a $70 \%$, but, for pump efficiencies lower than $50 \%$, it becomes the best choice. The reason for this is that the BWR for this fluid is low, and this means that any change of the pump polytropic efficiency has a minor impact on the efficiency. Propylene, which was the working fluid giving the best efficiency for the base case is still giving the best results for efficiencies higher than $70 \%$. However, when the pump efficiency drops below this value, it is the second worst working fluid. This gives insight about how important the pump efficiency is for the performance of the cycle. Despite transcritical cycles might appear as the most sensible to pump efficiency changes, some subcritical cycles can be more sensitive. The BWR can be used as a good indicator of the sensitivity of the cycle to the pump efficiency. At the same time, the BWR is a strong function of the critical temperature of the working fluid. Figure 5 also shows that R1234yf and propylene need to move from transcritical to subcritical conditions to reach the optimal performance when the pump efficiency is below $30 \%$, due to the high power consumption that operating at transcritical conditions with a low pump efficiency implies.

When comparing the obtained results with the literature, it was found that similar results were obtained in (Brosukiewicz-Gozdur, 2013). Even though this work includes the simulation of working fluids that were not considered by (Brosukiewicz-Gozdur, 2013), the same tendencies were obtained for the same studied working fluids, meaning that propylene is the working fluid with the highest specific power consumption, followed by the propane, while toluene presents the lowest one.

\subsection{Turbine stages analysis}

Since the specific work produced in the turbine is lower in the ORC than for gas and steam turbines, the expansion process can be handled in few stages. Assuming a fixed efficiency for the turbine (independent of factors such as the working fluid) leads to unrealistic results (Astolfi and Macchi, 2015). In this work, 1, 2 and 3 stage axial turbines have been studied in order to determine how this may affect the 
performance of the whole plant when different working fluids are used. To do so, the turbine efficiency was studied as a function of the Volume Ratio (which accounts for compressibility effects (Macchi, 2013)) and the Size Parameter (which accounts for the dimensions of the expander). Each pair of $S P$ and $V_{R}$ gives a specific turbine efficiency, which increases with lower $V_{R}$ and higher SP (Astolfi and Macchi, 2015). For the low density at the outlet of the turbine results into a high SP, which benefits the turbine efficiency. shows how the expander efficiency influences the overall power plant second law efficiency. Three different efficiencies were obtained for each studied working fluid, corresponding to a 1-, 2- or 3-stage expansion.

Results from Figure 6 show that increasing the number of stages leads to an increase of the expander efficiency for all the simulated working fluids, although some of them are more sensitive to this change than others. The best and worst working fluids are still the same (propylene and $\mathrm{CO}_{2}$ respectively) when moving from 1 to 3 expansion stages. Regarding the rest of the working fluids, some as acetone, butane, and MM are experiencing the greater improvements when increasing the turbine number of stages, while the R32 and the propyne are experiencing the lowest ones.

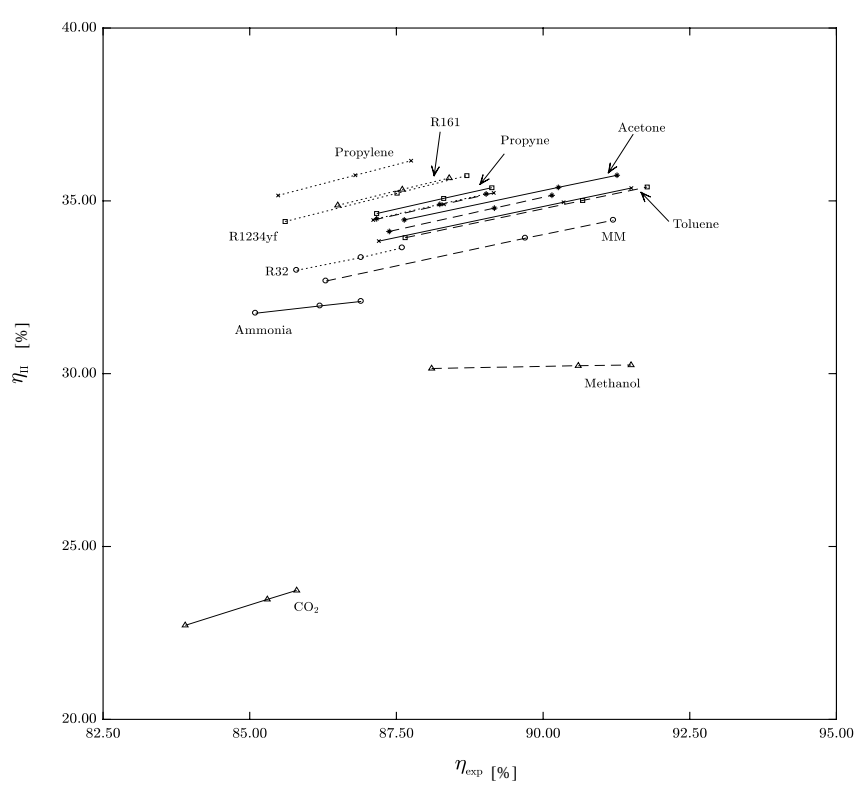

Figure 6. Influence of the expander efficiency on the second law efficiency of the whole power plant for different working fluids

Increasing the number of expansion stages for MM results into an increase of the turbine efficiency close to a 5\%, which implies a second law efficiency improvement of $1.76 \%$. Acetone also shows a great turbine efficiency improvement when increasing the number of stages, a $3.63 \%$, which results into a second law efficiency rise of $1.29 \%$.

Fluids such as R32 experience only an improvement of $1.83 \%$ on the turbine efficiency when moving from 1 to 3 stages of expansion, and this means a plant efficiency increase of only $0.65 \%$. On the other side, for $\mathrm{CO}_{2}$, even though the turbine efficiency experiences one of the highest improvements $(3.72 \%)$, the second law efficiency does not experience a great change (only $1 \%$ ).

Figure 7 shows how the SP and $V_{R}$ influence the efficiency of the turbine with only one stage for the different simulated working fluids. Working fluids with the highest efficiencies are the $\mathrm{H}_{2} \mathrm{O}$, methanol, acetone and toluene, while those ones with the lowest turbine efficiencies are $\mathrm{CO}_{2}$, ammonia and propylene. For the low density at the outlet of the turbine results into a high

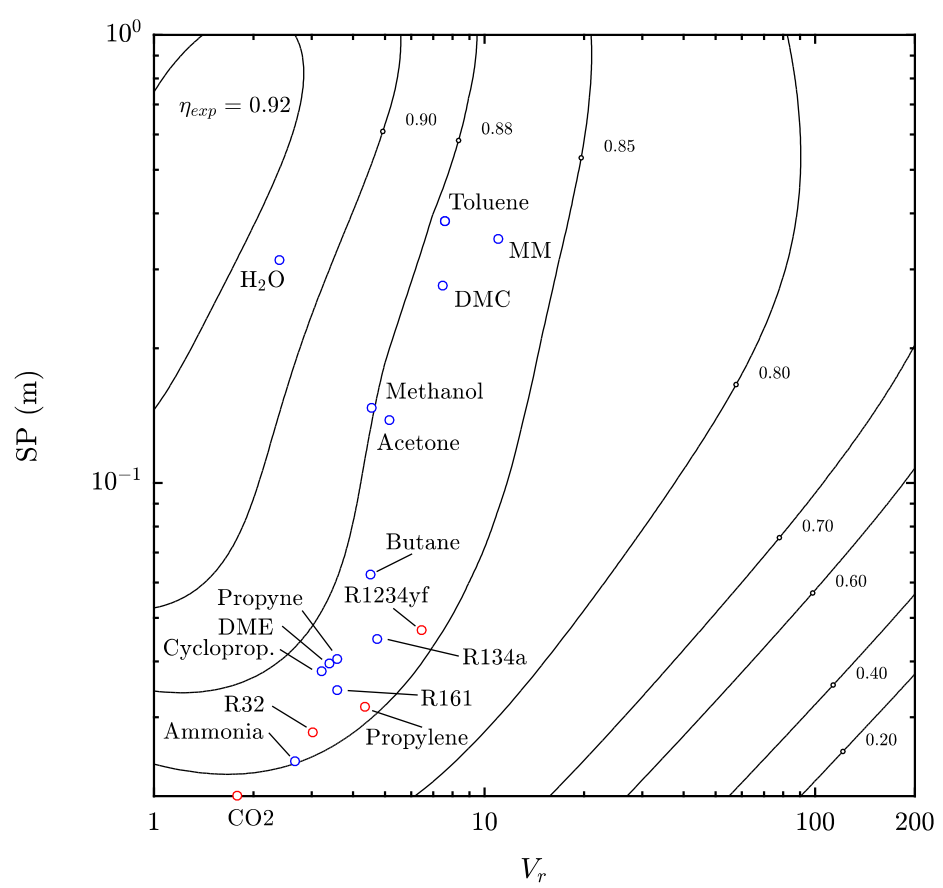

SP, which benefits the turbine efficiency.

Figure 7. Volume ratio and Size Parameter influence on the expander efficiency with one stage of expansion and for the different simulated working fluids.

\section{Conclusions}

After having carried out an analysis of the ORC for 39 different working fluids and under different cycle layouts and configurations, some conclusions have been reached:

1. Those working fluids with a critical temperature and maximum temperature of the cycle relationship between 0.93 and 1.02 (such as propylene and R1234yf) are showing the best results. Fluids with too low critical temperatures are giving the lowest efficiencies. 
2. Regarding the use of a recuperator, the dry and isentropic fluids are experiencing the highest efficiency improvements, while some wet fluids do not have potential to operate under this cycle layout (the second law efficiency for the whole power plant drops).

3. Fluids with a low critical temperature are much more dependent on the pump performance than those ones with a high critical temperature, due to the high Backwork Ratios of the former.

4. Increasing the number of stages for the turbine results into an efficiency improvement for all the studied cases. The degree of improvement is a function of the variation of the $V_{R}$ and SP.

5. It was demonstrated that $\mathrm{H}_{2} \mathrm{O}$ and $\mathrm{CO}_{2}$ are not suitable working fluids for an ORC with a lowtemperature heat source for low-capacity power plants. In case of co-generation for the cycle or higher power productions, their potential may increase, but this should be studied.

\section{Nomenclature}

Acronyms and symbols

\begin{tabular}{lll}
\hline BWR & Backwork Ratio & {$[\mathrm{kW} / \mathrm{kW}]$} \\
$\rho$ & Density & {$\left[\mathrm{kg} / \mathrm{m}^{3}\right]$} \\
$\eta$ & Efficiency & {$[\%]$} \\
$\mathrm{h}$ & Enthalpy & {$[\mathrm{J} / \mathrm{kg}]$} \\
$\dot{E}$ & Exergy flow & {$[\mathrm{kW}]$} \\
$\dot{Q}$ & Heat flow & {$[\mathrm{kW}]$} \\
$\dot{m}$ & Mass flow & {$[\mathrm{kg} / \mathrm{s}]$} \\
$\mathrm{MW}$ & Molecular Weight & {$[\mathrm{kg} / \mathrm{mole}]$} \\
$\dot{W}$ & Power & {$[\mathrm{kW}]$} \\
$\mathrm{p}$ & Pressure & {$[\mathrm{bar}]$} \\
$\mathrm{SP}$ & Size Parameter & {$[\mathrm{m}]$} \\
$\mathrm{T}$ & Temperature & {$[\mathrm{K}]$} \\
$V_{r}$ & Volume ratio & {$[-]$} \\
& & \\
GWP & Global Warming Potential \\
HC & Hydrocarbon & \\
HFC & Hydrofluorocarbon \\
HFO & Hydrofluoroolefin \\
ODP & Ozone Depletion Potential \\
ORC & Organic Rankine Cycle
\end{tabular}

\begin{tabular}{lll}
\multicolumn{1}{c}{ Subscripts } & \\
amb & & ambient \\
c & condenser \\
crit & critical \\
hot & hot-source \\
in & turbine inlet \\
$\mathrm{s}$ & isentropic \\
out & turbine outlet \\
rec & recuperator \\
turb & turbine \\
w.f & working fluid
\end{tabular}

\section{Acknowledgements}

This research was supported by the NTNU Department of Energy and Process Engineering, which provided the funding. We would like to thank them for having made this research and study possible.

\section{References}

Agromayor, R., Nord, L.O. (2017). Fluid selection and thermodynamic optimization of organic Rankine cycles for waste heat recovery applications. Energy Procedia (in press).

Astolfi, M., Macchi, E. (2015). Efficiency correlations for axial flow turbines working with non-conventional fluids. Asme Orc 2015 (83), 1-12.

Bao, J., Zhao, L. (August, 2013). A review of working fluid and expander selections for organic Rankine cycle. Renewable and Sustainable Energy Reviews (24), 325-342. doi: 10.1016/j.rser.2013.03.040

Borsukiewicz-Gozdur, A. (2013). Pumping work in the organic Rankine cycle. Applied Thermal Engineering (51), 781-786. doi: 10.1016/j.applthermaleng.2012.10.033

Colonna, P., Casati, E., Trapp, C., Mathijssen, T., Larjola, J., Turunen-Saaresti, T., Uusitalo, A. (2015). Organic Rankine Cycle Power Systems: From the Concept to Current Technology Applications, and an Outlook to the Future. Journal of Engineering for Gas Turbines and Power, 137, 100801-19. doi: 10.1115/1.4029884

Feng, Y., Hung, T., Greg, K., Zhang, Y., Li, B., Yang, J. (2015). Thermodynamic comparison between pure and mixture working fluids of organic Rankine cycles (ORCs) for low temperature waste heat recovery. Energy Conversion and Management. doi: 10.1016/j.enconman.2015.09.042

Frutiger, J., Andreasen, J., Liu, W., Spliethoff, H., Haglind, F., Abildskov, J., Sin, G. (2016). Working fluid selection for organic Rankine cycles - Impact of uncertainty of fluid properties. Energy (109), 987-997. doi: 10.1016/j.energy.2016.05.010

Haberle, F., Preisinger, M., \& Brüggemann, D. (2012). Zeotropic mixtures as working fluids in Organic Rankine Cycles for low-enthalpy geothermal resources. Renew Energy (37), 364-370. doi: 10.1016/j.renene.2011.06.044

Hærvig, J. S. (2016). Guidelines for optimal selection of working fluid for an organic Rankine cycle in relation to waste heat recovery. Energy (96), 592-602. doi: 10.1016/j.energy.2015.12.098

Hung, T.C., Wang, S.K., Kuo, C.H., Pei, B.S, Tsai, K.F. (2010). A study of organic working fluids on system efficiency of an ORC using low-grade energy sources. Energy (35), 1403-1411. doi: 10.1016/j.energy.2009.11.025

Landelle, A., Tauveron, N., Revellin, R., Haberschill, P., Colasson, S., Roussel, V. (2017). Performance investigation of reciprocating pump running with organic fluid for organic Rankine cycle. Applied Thermal Engineering (113), 962-969. doi: 10.1016/j.applthermaleng.2016.11.096

Liu, Q., Duan, Y., Yang, Z. (2013). Performance analyses of geothermal organic Rankine cycle with selected 
hydrocarbon working fluids. Energy (63), 123-132. doi: 10.1016/j.energy.2013.10.035

Macchi, E. (2013). The choice of working fluid: The most important step for a successful organic Rankine cycle (and an efficient turbine). Politecnico di Milano, Department of Energy, Milano.

Macchi, E., Astolfi, M. (2017). Organic Rankine Cycle (ORC) Power Systems. Technologies and Applications. (W. P. Energy, Ed.) Elsevier.

Maraver, D., Royo, J., Lemort, V., Quoilin, S. (2014). Systematic optimization of subcritical and transcritical organic Rankine cycles (ORCs) constrained by technical parameters in multiple applications. Applied Energy (117), 11-29. doi: 10.1016/j.apenergy.2013.11.076

Roy, J., Mishra, M., Ashok, M. (2011). Performance analysis of an Organic Rankine Cycle with superheating under different heat source temperature conditions. Applied Energy (88), 2995-3004. doi:

10.1016/j.apenergy.2011.02.042

Saleh, B., Koglbauer, G., Wendland, M., Fischer, J. (2007). Working fluids for low temperature organic Rankine cycles. Energy (32), 1210-1221. doi: 10.1016/j.energy.2006.07.001

Shu, G., Gao, Y., Tian, H., Wei, H., Liang, X. (2014). Study of mixtures based on hydrocarbons used in ORC (Organic Rankine Cycle) for engine waste heat recovery. Energy (74), 428-438. doi: 10.1016/j.energy.2014.07.007

Xu, J., Liu, C. (2013). Effect of the critical temperature of organic fluids on supercritical pressure Organic Rankine Cycles. Energy (63), 109-122. doi: 10.1016/j.energy.2013.09.068

Zhai, H., Shi, L., An, Q. (2014). Influence of working fluid properties on system performance and screen evaluation indicators for geothermal ORC (organic Rankine cycle) systems". Energy (74), 2-11. doi:

10.1016/j.energy.2013.12.030 